\title{
BMJ Open Reporting of conflicts of interest by authors of primary studies on health policy and systems research: a cross- sectional survey
}

\author{
Maram B Hakoum (D) , ${ }^{1}$ Lama Bou-Karroum, ${ }^{2,3}$ Mounir Al-Gibbawi, ${ }^{4}$ \\ Assem M Khamis (D) , ${ }^{1}$ Abdul Sattar Raslan, ${ }^{4}$ Sanaa Badour, ${ }^{5}$ Arnav Agarwal (D) , 6,7 \\ Fadel Alturki, ${ }^{4}$ Gordon Guyatt, ${ }^{7}$ Fadi El-Jardali, ${ }^{3,7,8}$ Elie A Akl (i) ${ }^{1,5,7}$
}

To cite: Hakoum MB, BouKarroum L, Al-Gibbawi M, et al. Reporting of conflicts of interest by authors of primary studies on health policy and systems research: a crosssectional survey. BMJ Open 2020;10:e032425. doi:10.1136/ bmjopen-2019-032425

- Prepublication history and additional material for this paper are available online. To view these files, please visit the journal online (http://dx.doi. org/10.1136/bmjopen-2019032425).

Received 27 June 2019 Revised 07 April 2020 Accepted 20 May 2020

Check for updates

\section{(c) Author(s) (or their} employer(s)) 2020. Re-use permitted under CC BY-NC. No commercial re-use. See rights and permissions. Published by BMJ.

For numbered affiliations see end of article.

Correspondence to

DrElie A Akl; ea32@aub.edu.Ib

\section{ABSTRACT}

Objectives The objective of this study was to assess the frequency and types of conflict of interest (COI) disclosed by authors of primary studies of health policy and systems research (HPSR).

Design We conducted a cross-sectional survey using standard systematic review methodology for study selection and data extraction. We conducted descriptive analyses.

Setting We collected data from papers published in 2016 in 'health policy and service journals' category in Web of Science database.

Participants We included primary studies (eg, randomised controlled trials, cohort studies, qualitative studies) of HPSR published in English in 2016 peerreviewed health policy and services journals.

Outcome measures Reported $\mathrm{COI}$ disclosures including whether authors reported COI or not, form in which COI disclosures were provided, number of authors per paper who report any type of $\mathrm{COI}$, number of authors per paper who report specific types and subtypes of $\mathrm{COI}$.

Results We included 200 eligible primary studies of which $132(66 \%)$ included COI disclosure statements of authors. Of the 132 studies, $19(14 \%)$ had at least one author reporting at least one type of $\mathrm{COI}$ and the most frequently reported type was individual financial $\mathrm{COI}(\mathrm{n}=15,11 \%)$. None of the authors reported individual intellectual COls or personal COls. Financial and individual COls were reported more frequently compared with non-financial and institutional COls.

Conclusion A low percentage of HPSR primary studies included authors reporting COI. Non-financial or institutional COls were the least reported types of COI.

\section{BACKGROUND}

Evidence-informed health policymaking aims to ensure that policymaking is well informed by the best available evidence. ${ }^{1}$ Evidence from health policy and systems research (HPSR) can inform health system policy decisions including who delivers health services and where, and how these services are financed and organised. ${ }^{2}{ }^{3}$ Furthermore.

\section{Strengths and limitations of this study}

- This is the first study to assess the frequency and types of conflict of interest (COI) disclosed by authors of primary studies of health policy and systems research.

- The study used a rigorous methodology that included a search strategy specific to health policy and services journals and duplicate study selection and data abstraction processes.

- We used a comprehensive framework for the classification of COI.

- The study focused on reported COI, thus these statements depend on journals' COI policy requirements, and whether authors' disclosures are accurate or complete remains uncertain.

policymakers are increasingly recognising the importance of the use of research evidence in improving health, reducing health inequities and contributing to economic development. ${ }^{45}$ However, conflict of interest (COI) of researchers may influence the conduct and reporting of HPSR.

COI is defined as 'a financial or intellectual relationship that may impact an individual's ability to approach a scientific question with an open mind'. 6 For instance, one study assessing the frequency and influence of financial COI on economic analyses in oncology found that the studies disclosing financial COI directly or indirectly consistently supported the sponsor's product. ${ }^{7}$ Additionally, Forsyth et al found that opinion articles sceptical of the use of systematic reviews for policymaking were more likely to have industry ties than articles supportive of their use. ${ }^{8}$

Reporting of COI in HPSR is important given its potential influence on public policy and decision-making. We previously assessed 


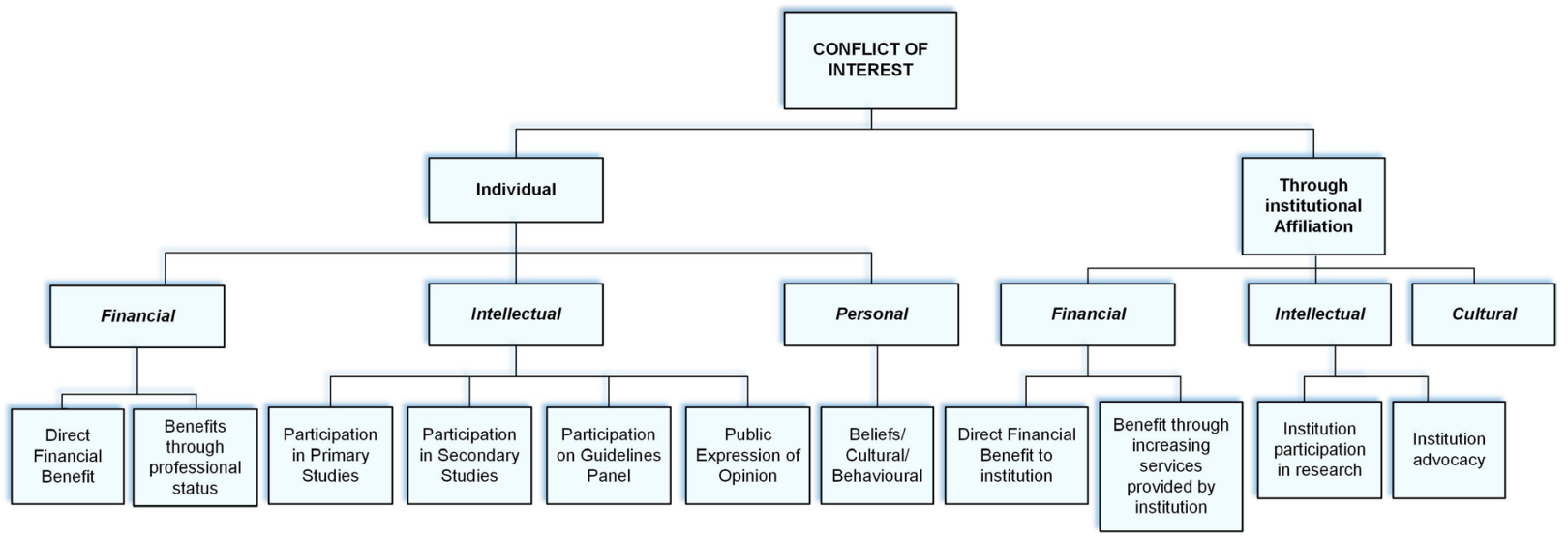

Figure 1 Classification of conflicts of interest.

the reporting of COI in HPSR systematic reviews. ${ }^{9}$ We found that $20 \%$ of those reviews did not include a COI disclosure statement, and only $15 \%$ of disclosure statements reported the existence of any COI. Furthermore, the reporting of COI in primary studies is important for both policymakers, relying on their findings for decisionmaking, as well as for authors of systematic reviews assessing the potential bias associated with the COI of study investigators. ${ }^{10}$ Therefore, this study aims to assess the types and frequency of COI disclosed by authors of primary studies of HPSR.

\section{METHODS}

\section{Design overview and definitions}

We conducted a cross-sectional survey using standard systematic review methodology for study selection and data extraction. We defined COI disclosure as the reporting of whether a COI exists or not. We classified the types of disclosed COIs as shown in figure 1 and detailed in online supplementary appendix S1. Our classification of COIs relies on a framework informed by a literature review, the findings of recent studies assessing COIs reported by authors of clinical systematic reviews, HPSR systematic reviews and randomised controlled trials $^{911} 12$ and the International Committee of Medical Journal Editors (ICMJE) COI disclosure form. ${ }^{13}$ We used the word 'loogly' to label 'any additional statement in the COI disclosure that attempts to downplay a disclosed relationship by suggesting that it is unrelated to COI (eg, 'this relationship did not influence the content of the manuscript'). ${ }^{11}$

\section{Eligibility criteria}

We included articles meeting the following eligibility criteria:

- Type of study: primary studies (eg, randomised controlled trials, cohort studies, qualitative studies). We excluded systematic and literature reviews, case studies, technical reports, conference reports, proceedings, editorials and opinion pieces; type of field: HPSR; we used the taxonomy of health systems topics used to code Health Systems Evidence database of McMaster Health Forum to assess eligibility: governance, financial, delivery arrangements and implementation strategies. ${ }^{14} 15$ Governance arrangements cover five topics: policy authority, organisational authority, commercial authority, professional authority, and consumer and stakeholder involvement. Financial arrangements include topics on financing systems, funding organisations, remuneration providers, purchasing products and services, and incentivising consumers. Delivery arrangements cover topics related to how care is designed to meet consumers' needs, by whom care is provided, where care is provided and with what supports is care provided. Implementation strategies comprise topics on consumer-targeted strategy, provider-targeted strategy and organisationtargeted strategy.

- Articles published in English in 2016.

\section{Search strategy}

We searched for papers published in peer-reviewed health policy and services journals. We ran the search in the Web of Science database limiting to 'Health Policy and Services' journal category, 'article' document type, English language and to the year 2016. Online supplementary appendix S2 presents the detailed search strategy.

\section{Selection process}

We drew a random sample of 200 papers from the set of citations retrieved by the search to undergo the selection process using an online random sequence generator (www.random.org/sequences). This sample of 200 primary studies is a subset of our previously published study on the reporting of funding in HPSR. ${ }^{16}$

Citations were exported to EndNote X7.5 software (Thomson Reuters, Philadelphia, PA, USA). Reviewers completed calibration exercises before starting the selection process. Two reviewers screened title and abstracts for eligibility in duplicate and independently using EndNote. We ensured that papers retrieved by our search were effectively on HPSR. We retrieved the full text of citations judged as potentially eligible by at least one of the two reviewers. The two reviewers screened the full texts 


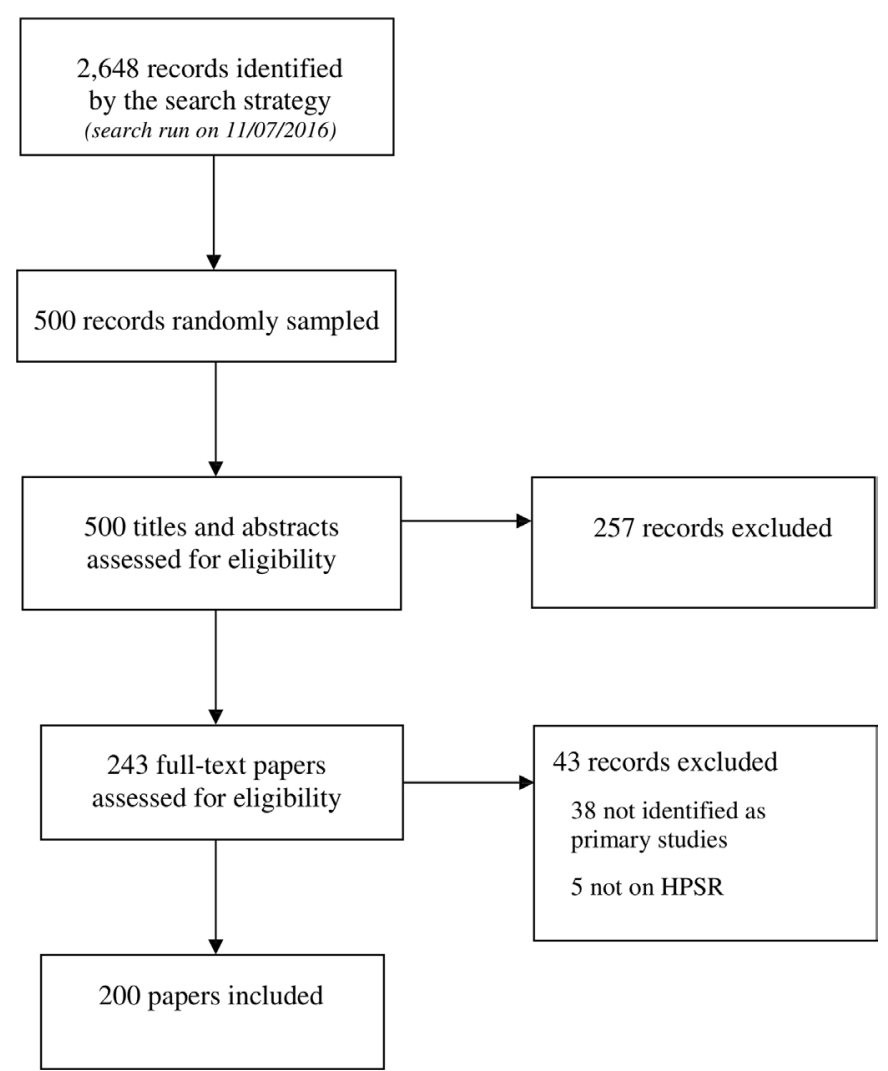

Figure 2 Study flow diagram. HPSR, health policy and systems research.

in duplicate and independently. The reviewers resolved their disagreements by discussion, and consulted a third reviewer when consensus could not be reached. We used a standardised and pilot-tested full-text screening form. We recorded reasons for exclusion and summarised the selection process results in a Preferred Reporting Items for Systematic Reviews and Meta-Analyses study flow diagram. ${ }^{17}$

\section{Data extraction process}

We developed and pilot-tested a standardised data extraction form with detailed instructions (see online supplementary appendix S3). Two teams of eight reviewers completed calibration exercises and extracted data in duplicate and independently. Reviewers extracted study data using Research Electronic Data Capture tool, a secure, web-based application designed to support data capture for research studies. ${ }^{18}$ The reviewers compared results and resolved disagreements through discussion, or with the help of a third person when consensus could not be reached.

\section{Extracted data}

We extracted the following general characteristics of each article:

- Number of authors.

- Reported affiliation(s) of first and last authors (private or public academic institution, government, not-for-profit organisation, private for profit, intergovernmental).

- Country of affiliation of the first author and its classification (as per World Bank list of economies issued in September 2016).

- Health systems arrangement of the paper (governance, financial, delivery arrangements and implementation strategies).

We extracted the following characteristics of the reported COI disclosures (as defined above):

- Whether authors reported COI or not.

- Form in which COI disclosures were provided (a narrative statement, an online document, available on request).

- Number of authors per paper who report any type of COI.

- Number of authors per paper who report each specific type of COI, and when applicable, the different subtypes of COI.

- Whether the paper reports relevant characteristics of the COI (source, monetary value, duration).

- Whether individuals other than the authors provided COI disclosures (eg, editors, peer reviewers, external writers, others).

We extracted the following information on the characteristics of the journal:

- Impact factor.

- Existence of a COI disclosure policy.

\section{Data analysis}

For eligible articles, we conducted descriptive analyses, focusing on the reported COI disclosures. For continuous variables, we present summary data as medians and quartiles since the application of the Kolmogorov-Smirnov test did not demonstrate normality. We presented the results for categorical variables as frequencies and percentages, and analysed them using the $\chi^{2}$ test or, if the expected event number proved less than 5 , the Fisher's exact test. We considered a $\mathrm{p}$ value of $<0.05$ as statistically significant. We performed the analysis using SPSS V.21.0 for Windows (SPSS).

\section{RESULTS}

Out of the 2648 citations identified, we included 200 eligible primary studies that were published in 55 'Health Policy \& Services' journals. Figure 2 shows the study flow diagram.

\section{General characteristics of the included primary studies}

Table 1 presents the general characteristics of the included primary studies. The median number of authors per study was 4 . The majority of studies were conducted by authors affiliated with institutions located in high-income countries $(92 \%)$ where most articles were conducted in the USA ( $54 \%$ ) followed by UK ( $8 \%$ ). Most articles addressed the topic of delivery arrangements (72\%). Most first 
Table 1 General characteristics of the included primary studies $(n=200)$

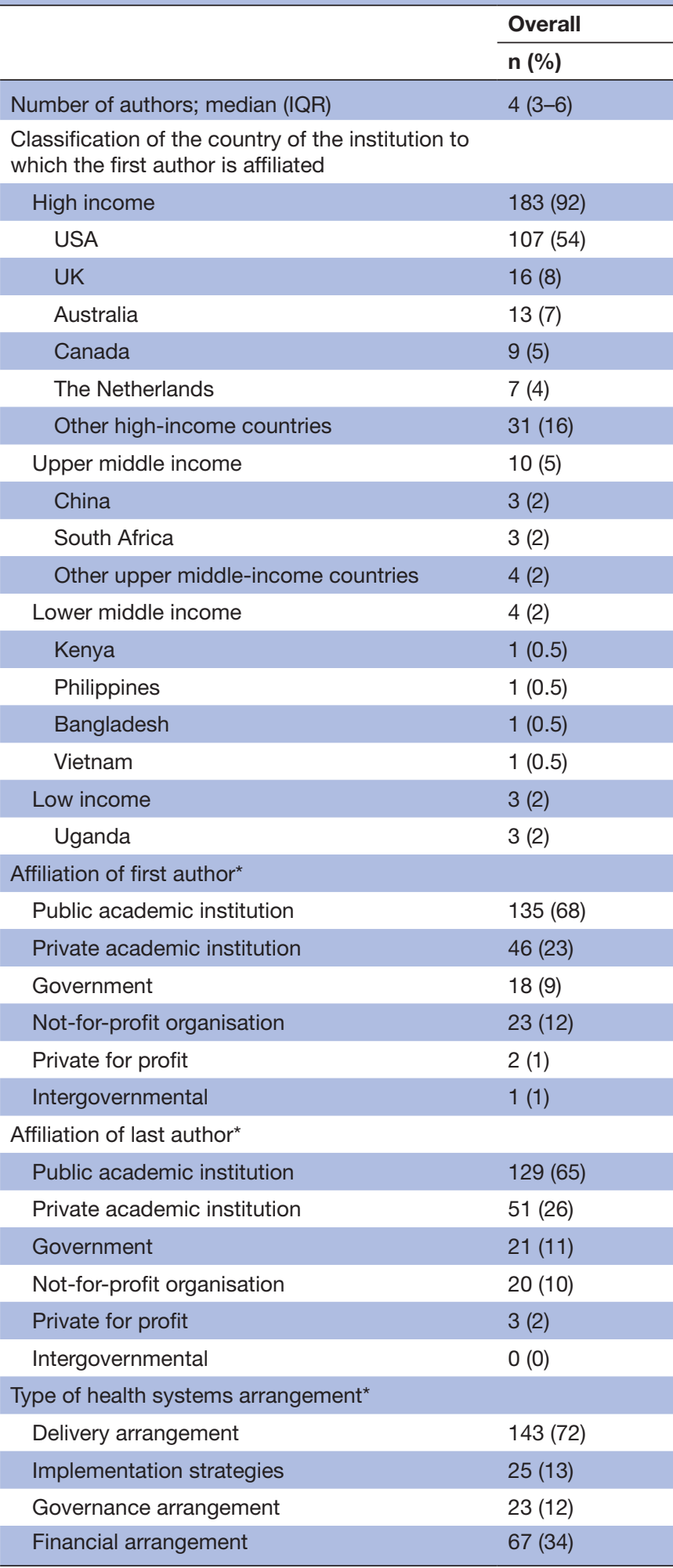

*Studies may have more than one option that applies.
Table 2 Reporting by primary study authors of the different types of conflict of interest (COI) $(n=132)$

\begin{tabular}{ll}
$\begin{array}{l}\text { Studies } \\
\text { with at least } \\
\text { one author } \\
\text { reporting a } \\
\text { specific type } \\
\text { of COI* } \\
\text { n (\%) }\end{array}$ & $\begin{array}{l}\text { Distribution of } \\
\text { the percentage } \\
\text { of authors per } \\
\text { study reporting } \\
\text { that type of } \\
\text { COI† } \\
\text { Median (IQR) }\end{array}$ \\
\hline $19(14)$ & $25(17-50)$ \\
$15(11)$ & $25(15-50)$
\end{tabular}

$\begin{array}{lll}\text { At least one type } & 19(14) & 25(17-50) \\ \text { Individual financial (direct } & 15(11) & 25(15-50)\end{array}$

benefit)

\begin{tabular}{|c|c|c|}
\hline $\begin{array}{l}\text { Individual financial (benefit } \\
\text { through professional status) }\end{array}$ & $0(0)$ & N/A \\
\hline Individual intellectual & $0(0)$ & N/A \\
\hline Individual personal & $0(0)$ & N/A \\
\hline Institutional financial & $2(2)$ & $\ddagger$ \\
\hline Institutional intellectual & $3(2)$ & $\S$ \\
\hline Institutional cultural & $0(0)$ & $\mathrm{N} / \mathrm{A}$ \\
\hline 'Other types'ף & $4(3)$ & $30(18-85)$ \\
\hline Provided a 'loogly statement' & $3(2)$ & ** \\
\hline
\end{tabular}

${ }^{*}$ One study can have authors reporting more than one type of COI.

†Calculated using the number of papers with at least one author reporting the specific type of $\mathrm{COI}$ (ie, papers counted in the preceding column) as the denominator.

$\ddagger$ Authors of only two studies reported institutional financial COI, with the percentages being $20 \%$ and $100 \%$.

$\S$ Authors of only three studies reported institutional intellectual $\mathrm{COI}$, with the percentages being $20 \%, 25 \%$ and $33 \%$.

I"Other types' of COls included: 'implementing national clinical audit' ( $n=1$ ), 'non-compensated affiliations' $(n=1)$, 'attended meetings' $(n=1)$ and relationship with a publishing entity $(n=1)$. We consider these as individual and non-financial types of COI. **Authors of only three studies provided a 'loogly statement', with the percentages being $10 \%, 25 \%$ and $100 \%$. $\mathrm{N} / \mathrm{A}$, not applicable.

authors and last authors were affiliated with public academic institutions ( $68 \%$ and $65 \%$, respectively).

\section{Characteristics of the reported COI disclosures}

Of the 200 primary studies, 66\% (132/200) included COI disclosure statements of authors. All but one study provided COI disclosures narratively in the main document; the single study provided them in an online form that was not accessible. None of the included studies reported COI by individuals other than the authors (eg, editors or peer reviewers).

Table 2 presents the reporting of the different types of COI in the 132 studies that included COI disclosure statements. Of these 132 studies that included COI disclosure statements, $19(14 \%)$ had at least one author reporting at least one type of COI while $113(86 \%)$ studies had their authors reporting that they had no COI. The most frequently reported type was individual financial COI $(\mathrm{n}=15,11 \%)$, with the median percentage of authors reporting this type of COI being $25 \%$. None of the authors 
reported individual intellectual COIs or personal COIs. Of the 132 primary studies that provided COI disclosure statements, more had at least one author reporting financial COIs compared with non-financial COIs $(n=16,12 \%$ vs $n=3,2 \% ; p=0.04)$. More studies had at least one author reporting individual COIs compared with institutional COIs $(n=15,11 \%$ vs $n=5,4 \%$; $=0.01)$.

\section{Individual financial $\mathrm{COI}$}

Table 3 presents the reporting of the different subtypes of individual financial COI in the 15 primary studies with at least one author reporting individual financial COI. The two most frequently reported subtypes were 'personal fees' $(n=9,60 \%)$ and 'grant' $(n=6,40 \%)$. The median percentages of authors reporting these two subtypes were $20 \%$ and $18 \%$, respectively.

Of the 15 studies with at least one author reporting individual financial COI, 14 reported the source of financial COI. Only two of these 14 studies specified the relationship of the source to the field under study; in both cases, the sources produced a product not the subject of the study but under the same field. Only one of the 15 studies reported on the timing of the conflicted relationship relative to the conduct of the study; in that case, the relationship occurred during the conduct of the study. None of the studies reported on the monetary value of the financial COI.

\section{Characteristics of the journals}

The median impact factor of the 55 journals that published the included primary studies was 1.66 ( $\mathrm{IQR}=1.36-2.41$ ). Ninety-six per cent $(53 / 55)$ of the journals had a COI disclosure policy requiring authors to report their COI. Of the 68 papers that did not include a COI statement, $90 \%(61 / 68)$ were published in journals that did have a COI disclosure policy. The percentage of papers that included a COI statement was $68.2 \%$ in journals with a COI disclosure policy and $12.5 \%$ in journals without a COI disclosure policy $(\mathrm{p}=0.012)$. We provided the list of the 55 journals that published the included primary studies in online supplementary appendix S4.

\section{DISCUSSION}

\section{Summary of findings}

In summary, $66 \%$ of 200 HPSR primary studies included COI disclosure statements of authors, with only one using an inaccessible online disclosure form. Of these studies, $14 \% \mathrm{had}$ at least one author reporting at least one type of COI. Most frequently, the authors reported individual financial COI. Very few studies reported non-financial or institutional COIs. The two most frequently reported subtypes of individual financial COI were 'personal fees' and 'grant'. None of the studies reported on the monetary value of the financial COI, or provided disclosure by individuals other than the authors such as editors or reviewers.

\section{Strengths and limitations}

This is the first study to assess the frequency and types of COI disclosed by authors of primary studies of HPSR. We have used a rigorous methodology that included a search strategy specific to health policy and services journals and duplicate study selection and data abstraction processes. We used a comprehensive framework for the classification of COI used in previous studies. ${ }^{911} 12$ Our study focused on reported COI, thus these statements depend on journals' COI policy requirements, and whether authors' disclosures are accurate or complete remains uncertain.

\section{Comparison to other studies}

Our findings, in relation to similar studies, demonstrate that COI disclosure statements are less frequently included in HPSR primary studies (66\%) compared with HPSR systematic reviews $(80 \%)$, clinical randomised controlled trials $(94 \%)$ and clinical systematic reviews $(97 \%)$ (figure 3). ${ }^{911} 12$ Factors that may be contributing to these differences include the less rigorous COI policies in HPSR journals compared with core clinical journals, and potentially a less strict implementation: $93 \%$ of

Table 3 Reporting of primary study authors of different subtypes of individual financial conflict of interest (COI) $(n=15)$

\begin{tabular}{lll}
\hline & $\begin{array}{l}\text { Studies } \\
\text { with at least } \\
\text { one author } \\
\text { reporting } \\
\text { the subtype } \\
\text { of individual } \\
\text { financial } \\
\text { COI* } \\
\mathbf{n}(\%)\end{array}$ & $\begin{array}{l}\text { Distributions of } \\
\text { the percentage } \\
\text { of authors per } \\
\text { study reporting } \\
\text { that subtype of } \\
\text { COI† } \\
\text { Median (IQR) }\end{array}$ \\
\hline Grant & $6(40)$ & $18(9-27)$ \\
\hline Employment & $2(13)$ & $\ddagger$ \\
\hline $\begin{array}{l}\text { Personal fees (other than } \\
\text { employment) }\end{array}$ & $9(60)$ & $20(12-38)$ \\
\hline Non-monetary support & $1(7)$ & $\S$ \\
\hline $\begin{array}{l}\text { Study supplies/services } \\
\text { Patent(s) }\end{array}$ & $0(0)$ & N/A \\
\hline $\begin{array}{l}\text { Stocks, bonds, stock } \\
\text { options, other securities }\end{array}$ & $3(0)$ & N/A \\
\hline 'Other subtypes' & $0(0)$ & N/A \\
\hline
\end{tabular}

*One study can have authors reporting more than one type of $\mathrm{COI}$. †Calculated using the number of papers with at least one author reporting the specific type of $\mathrm{COI}$ (ie, papers counted in the preceding column) as the denominator.

$\ddagger$ Authors of only two studies reported 'Employment', with the percentages being $50 \%$ and $100 \%$.

$\S$ Authors of only one study reported 'Non-monetary support', with the percentage being $17 \%$.

TAuthors of only three studies reported 'Stocks, bonds, stock options, other securities', with the percentages being 20\%, 25\% and $33 \%$.

N/A, not applicable. 


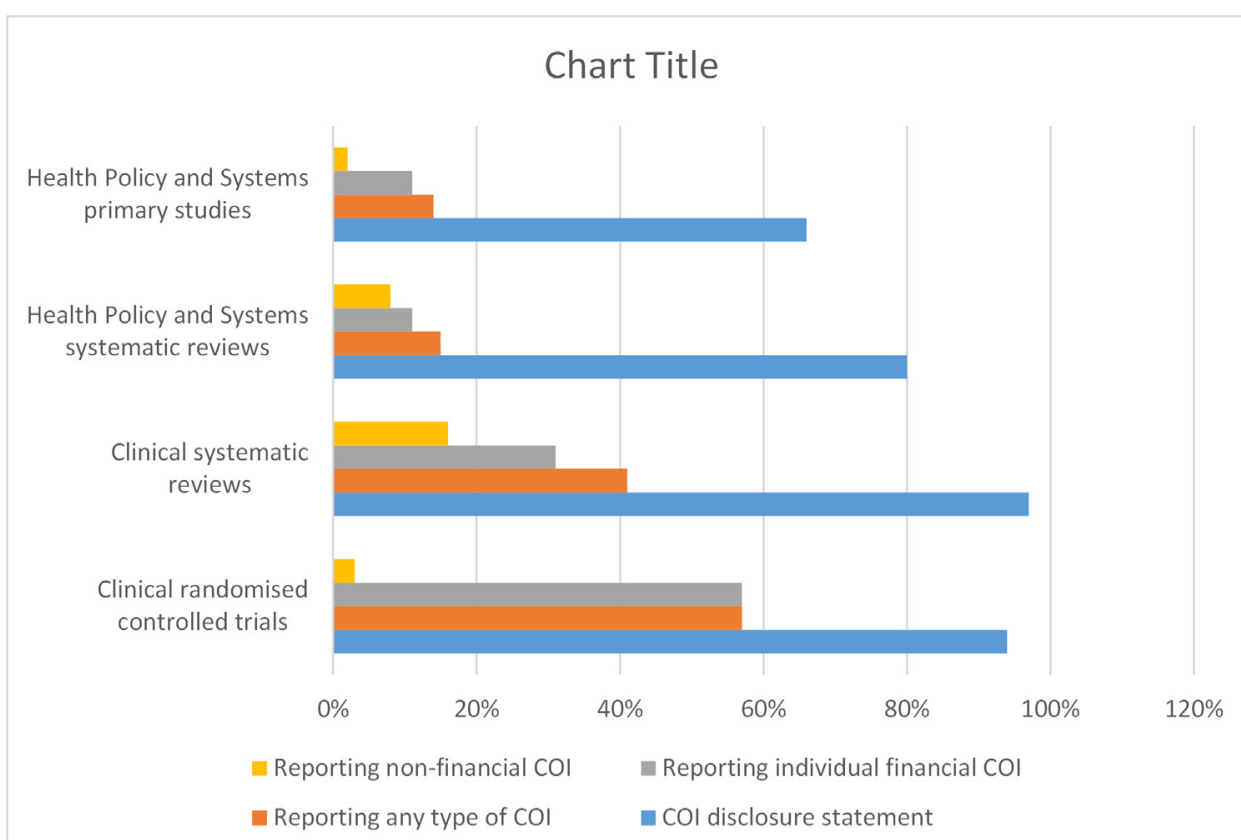

Figure 3 Chart comparing the reporting of financial and non-financial COls in different types of publications. The denominator for the reporting of the different types of $\mathrm{COI}$ is the number of studies that included a COI disclosure statement. COI, conflict of interest.

HPSR journals (including the 55 journals that published the primary studies included in this study) have a COI disclosure policy compared with $99 \%$ for core clinical journals. $^{19} 20$

The percentage of authors reporting any type of COI in HPSR primary studies (14\%) was comparable to that of HPSR systematic reviews (15\%). However, that percentage is much lower compared with that of clinical systematic reviews $(41 \%)$ and clinical trials $(57 \%) .{ }^{911} 12$ 'Possible explanations for this low rate of disclosure could be either an actual low prevalence of COI in this field, or an underreporting by HPSR authors of their COIs'. Indeed, an increasing number of studies are using resources such as the Open Payment database to verify the accuracy of the COI disclosures of health researchers. ${ }^{21-24}$ They are consistently showing that researchers tend to under-report their COIs (up to $81 \%$ in one study ${ }^{25}$ ).

Reporting of financial COI was higher than nonfinancial COI in HPSR primary studies. This is consistent with the findings of previous studies that focused on COI reporting in HPSR systematic reviews, clinical systematic reviews and randomised controlled trials. ${ }^{9} 1112$ Although this might reflect how frequently these types of COI exist, it might also be that authors are less aware of the concept of non-financial COI, or of what exactly qualifies as a nonfinancial COI. Another explanation could be related to the extent of use of standard COI disclosure forms: we found that only one study used a standardised form to report COI, compared with $12 \%$ in clinical trials. ${ }^{12}$

\section{Implications for practice and research}

As HPSR may be used to inform policy decisions, COI of HPSR authors may bias their research output and subsequently lead to misguided public policies and decisions. $^{2627}$ For example, Bes-Rastrollo et al found that financial COI may bias findings of systematic reviews of the effects of sugar-sweetened beverages consumption on weight gain and obesity. ${ }^{28}$ In turn, such biased conclusions might adversely influence policymaking related to regulation of sugar-sweetened beverages. Consequently, the appropriate disclosure and management of COIs are essential for the credibility and trust in HPSR, and hence might increase its uptake in policymaking. For that reason, HPSR journals strengthen their COI disclosure policies, and the implementation of existing policies. One approach to help authors better recognise and disclose their COIs would be to develop a standardised COI disclosure form similar to that of the ICMJE but more specific to HPSR. Journals publishing HPSR should also consider collecting and publishing the COIs of editors and peer reviewers. Future research should investigate the reasons behind the higher reporting of financial COI compared with non-financial COI in HPSR primary studies. Investigation of the accuracy and completeness of reporting of COI may also provide insight into the low rates of disclosed COI.

\section{Author affiliations}

${ }^{1}$ Clinical Research Institute, American University of Beirut, Beirut, Lebanon

${ }^{2}$ Center for Systematic Reviews for Health Policy and Systems Research, American University of Beirut, Beirut, Lebanon

${ }^{3}$ Department of Health Management and Policy, Faculty of Health Sciences, American University of Beirut, Beirut, Lebanon

${ }^{4}$ Faculty of Medicine, American University of Beirut, Beirut, Lebanon

${ }^{5}$ Department of Internal Medicine, American University of Beirut Medical Center,

Beirut, Lebanon

${ }^{6}$ Faculty of Medicine, University of Toronto, Toronto, Ontario, Canada 
${ }^{7}$ Department of Health Research Methods, Evidence, and Impact, McMaster University, Hamilton, Ontario, Canada

${ }^{8}$ Knowledge to Policy (K2P) Center, Faculty of Health Sciences, American University of Beirut, Beirut, Lebanon

Contributors MBH, LBK, FEJ, GG and EAA conceived and designed the study. MBH coordinated the study throughout. EAA had full access to all of the data in the study and takes responsibility for the integrity of the data and the accuracy of the data analysis. MBH and LBK ran the search and study selection processes. MBH, LBK, MAG, AMK, ASR, SB, AA and FA extracted the data. MBH, LBK and EAA analysed and interpreted the data. MBH and LBK wrote the first draft of the manuscript with EAA. All authors critically revised the manuscript and approved the final version. The lead author (EAA) affirms that this manuscript is an honest, accurate and transparent account of the study being reported; that no important aspects of the study have been omitted; and that any discrepancies from the study as planned have been explained.

Funding This work was supported by the American University of Beirut Faculty of Medicine's Medical Practice Plan (MPP) funds.

Competing interests $\mathrm{MBH}, \mathrm{GG}$ and EAA have competing interests related to their research in the area of conflicts of interest.

Patient and public involvement Patients and/or the public were not involved in the design, or conduct, or reporting, or dissemination plans of this research.

Patient consent for publication Not required.

Provenance and peer review Not commissioned; externally peer reviewed.

Data availability statement All data relevant to the study are included in the article or uploaded as supplementary information.

Open access This is an open access article distributed in accordance with the Creative Commons Attribution Non Commercial (CC BY-NC 4.0) license, which permits others to distribute, remix, adapt, build upon this work non-commercially, and license their derivative works on different terms, provided the original work is properly cited, appropriate credit is given, any changes made indicated, and the use is non-commercial. See: http://creativecommons.org/licenses/by-nc/4.0/.

\section{ORCID iDs}

Maram B Hakoum http://orcid.org/0000-0003-0105-1937

Assem M Khamis http://orcid.org/0000-0002-5567-7065

Arnav Agarwal http://orcid.org/0000-0002-0931-7851

Elie A Akl http://orcid.org/0000-0002-3444-8618

\section{REFERENCES}

1 Oxman AD, Lavis JN, Lewin S, et al. Support tools for evidenceinformed health Policymaking (STP) 1: what is evidence-informed policymaking? Health Res Policy Syst 2009;7 Suppl 1:S1.

2 Gilson L, Hanson K, Sheikh K, et al. Building the field of health policy and systems research: social science matters. PLoS Med 2011;8:e1001079.

3 Koon AD, Rao KD, Tran NT, et al. Embedding health policy and systems research into decision-making processes in low- and middle-income countries. Health Res Policy Syst 2013;11:30.

4 Lavis JN, Posada FB, Haines A, et al. Use of research to inform public policymaking. The Lancet 2004;364:1615-21.

5 El-Jardali F, Lavis JN, Ataya N, et al. Use of health systems evidence by policymakers in eastern Mediterranean countries: views, practices, and contextual influences. BMC Health Serv Res 2012;12:200.

6 Schünemann HJ, Osborne M, Moss J, et al. An official American thoracic Society policy statement: managing conflict of interest in professional societies. Am J Respir Crit Care Med 2009;180:564-80.

7 Jang S, Chae YK, Majhail NS. Financial conflicts of interest in economic analyses in oncology. Am J Clin Oncol 2011;34:524-8.
8 Forsyth SR, Odierna DH, Krauth D, et al. Conflicts of interest and critiques of the use of systematic reviews in policymaking: an analysis of opinion articles. Syst Rev 2014;3:122.

9 Bou-Karroum L, Hakoum MB, Hammoud MZ, et al. Reporting of financial and Non-financial conflicts of interest in systematic reviews on health policy and systems research: a cross sectional survey. Int $J$ Health Policy Manag 2018;7:711-7.

10 Elia N, von Elm E, Chatagner A, et al. How do authors of systematic reviews deal with research malpractice and misconduct in original studies? A cross-sectional analysis of systematic reviews and survey of their authors. BMJ Open 2016;6:e010442.

11 Hakoum MB, Anouti S, Al-Gibbawi M, et al. Reporting of financial and non-financial conflicts of interest by authors of systematic reviews: a methodological survey. BMJ Open 2016;6:e011997.

12 Hakoum MB, Jouni N, Abou-Jaoude EA, et al. Authors of clinical trials reported individual and financial conflicts of interest more frequently than institutional and nonfinancial ones: a methodological survey. J Clin Epidemiol 2017;87:78-86.

13 Gallagher SS. Characteristics of evaluated childhood agricultural safety interventions. J Agromedicine 2012;17:109-26.

14 Kendrick D, Barlow J, Hampshire A, et al. Parenting interventions and the prevention of unintentional injuries in childhood: systematic review and meta-analysis. Child Care Health Dev 2008;34:682-95.

15 Lavis JN, Wilson MG, Moat KA, et al. Developing and refining the methods for a 'one-stop shop' for research evidence about health systems. Health Res Policy Syst 2015;13:10.

16 Khamis AM, Bou-Karroum L, Hakoum MB, et al. The reporting of funding in health policy and systems research: a cross-sectional study. Health Res Policy Syst 2018;16:83-4.

17 Moher D, Liberati A, Tetzlaff J, et al. Preferred reporting items for systematic reviews and meta-analyses: the PRISMA statement. PLoS Med 2009;6:e1000097.

18 Harris PA, Taylor R, Thielke R, et al. Research electronic data capture (REDCap)--a metadata-driven methodology and workflow process for providing translational research informatics support. J Biomed Inform 2009;42:377-81.

19 Khamis AM, Hakoum MB, Bou-Karroum L, et al. Requirements of health policy and services journals for authors to disclose financial and non-financial conflicts of interest: a cross-sectional study. Health Res Policy Syst 2017;15:80.

20 Shawwa K, Kallas R, Koujanian S, et al. Requirements of clinical journals for authors' disclosure of financial and NonFinancial conflicts of interest: a cross sectional study. PLoS One 2016;11:e0152301.

21 Boddapati V, Fu MC, Nwachukwu BU, et al. Accuracy between AJSM Author-Reported disclosures and the centers for Medicare and Medicaid services open payments database. Am J Sports Med 2018:46:969-76.

22 Cherla DV, Viso CP, Olavarria OA, et al. The impact of financial conflict of interest on surgical research: an observational study of published manuscripts. World J Surg 2018;42:2757-62.

23 Jimbo M, Granberg CF, Osumah TS, et al. Discrepancies in self-reported and actual conflicts of interest for robotic pediatric urological surgery. J Urol 2019;201:393-9.

24 Luce EA, Jackman CA. Disclosure of financial conflicts of interest in plastic and reconstructive surgery. Plast Reconstr Surg 2017;140:635-9.

25 Patel SV, Yu D, Elsolh B, et al. Assessment of conflicts of interest in robotic surgical studies: validating author's Declarations with the open payments database. Ann Surg 2018;268:86-92.

26 Mandrioli D, Kearns CE, Bero LA. Relationship between research outcomes and risk of bias, study sponsorship, and author financial conflicts of interest in reviews of the effects of artificially sweetened beverages on weight outcomes: a systematic review of reviews. PLoS One 2016;11:e0162198.

27 Scollo Met al. Review of the quality of studies on the economic effects of smoke-free policies on the hospitality industry. Tob Control 2003;12:13-20.

28 Bes-Rastrollo M, Schulze MB, Ruiz-Canela M, et al. Financial conflicts of interest and reporting bias regarding the association between sugar-sweetened beverages and weight gain: a systematic review of systematic reviews. PLoS Med 2013;10:e1001578-e78. 